\title{
Role of CIMT, eGFR, and Serum HbA1c in Predicting CAD in Non-Diabetic Patients Undergoing Elective Coronary Angiography
}

\author{
C. Kapil, D. Rajasekhar*, V. Vanjakshamma, D. Kranthichaitanya, C. H. Narendra \\ Department of Cardiology, Sri Venkateswara Institute of Medical Sciences, Tirupati, India \\ Email: *cardiologysvims@gmail.com
}

How to cite this paper: Kapil, C., Rajasekhar, D., Vanjakshamma, V., Kranthichaitanya, D. and Narendra, C.H. (2018) Role of CIMT, eGFR, and Serum HbAlc in Predicting CAD in Non-Diabetic Patients Undergoing Elective Coronary Angiography. World Journal of Cardiovascular Diseases, 8, 1-10.

https://doi.org/10.4236/wjcd.2018.81001

Received: November 29, 2017

Accepted: January 8, 2018

Published: January 11, 2018

Copyright $\odot 2018$ by authors and Scientific Research Publishing Inc. This work is licensed under the Creative Commons Attribution International License (CC BY 4.0).

http://creativecommons.org/licenses/by/4.0/

(c) (i) Open Access

\begin{abstract}
Background: Pre-diabetic state, renal function, atherosclerosis burden are the major predictors for development of coronary artery disease (CAD). Present study aims to analyze the role of carotid intima-media thickness (CIMT), glomerular filtration rate (eGFR) and serum glycosylated hemoglobin (HbAlc) levels in predicting $\mathrm{CAD}$ on coronary angiography in non-diabetic patients. Methods: CAD and its severity according to SYNTAX score (SX score) was evaluated in 450 non-diabetic patients hospitalized with acute coronary syndrome or stable angina and underwent coronary angiography. CIMT, eGFR, and serum $\mathrm{HbAlc}$ values were obtained during admission. Spearman correlation and linear regression were used in the analysis of the data. Receiver operating characteristic (ROC) curve was constructed to calculate cutoff values, area under curve (AUC), sensitivity and specificity. Results: Statistically significant positive correlation was observed between $\mathrm{HbAlc}$ ( $\mathrm{r}: 0.242, p=$ $0.001)$; CIMT (r: 0.231, $p=0.001$ ), patient's age ( $\mathrm{r}: 0.148, p=0.002)$ and SX score, whereas eGFR was negatively correlated $(\mathrm{r}:-0.148, p=0.002)$. On regression analysis, CIMT, eGFR, HbAlc and patient's age collectively predicted $36 \%$ of change in the SYNTAX score. Patient's age $>56$ years $($ AUC $=0.622)$, CIMT $>0.86 \mathrm{~mm}(\mathrm{AUC}=0.642), \mathrm{HbAlc}>6(\mathrm{AUC}=0.620), \mathrm{eGFR}<92$ $\mathrm{ml} / \mathrm{min} / 1.73 \mathrm{~m}^{2}(\mathrm{AUC}=0.601)$ were the cutoff values on ROC curve analysis. CIMT, HbA1c had relatively high specificity $(88.5 \%, 90.2 \%$ respectively) and eGFR had relatively high sensitivity (71.3\%) among the studied variables in predicting CAD in present study. Conclusions: CIMT, HbAlc, eGFR and patient's age at the time of admission predict CAD in non-diabetic patients undergoing coronary angiography.
\end{abstract}

\section{Keywords}

CAD, CIMT, eGFR, HbA1c, SYNTAX Score 


\section{Introduction}

Over the last decade, cardiovascular disease (CVD) especially coronary artery disease (CAD) has become the largest cause of death worldwide. Recent estimates suggest that 80 percent of CVD deaths occur in developing countries with substantial contribution from India [1]. In India, the estimated adult prevalence (of the age $>30$ year) of CAD is around $8-10$ percent in urban settings and $3-4$ percent in rural areas, reflecting a rise of six-fold and two-fold respectively between 1960 and 2000 [2].

The incidence of CAD is likely to increase further because of rapid urbanization and its accompanying lifestyle changes, including changes in diet, physical inactivity, drug and alcohol intake, as well as an increase in the prevalence of diabetes mellitus (DM) [3] [4]. A positive association has been reported between the duration of $\mathrm{DM}$ and the risk of developing CAD [5]. An independent association between fatal CAD and increasing duration of DM has been shown in men [6]. Some studies suggest that CAD and glycosylated hemoglobin (HbA1c) are predictors of cardiovascular mortality [7] [8]. In community-based studies, decreased glomerular filtration rate (GFR) and proteinuria were both found to be independently associated with CAD [9] [10] [11]. The risk for CAD increases gradually with the decline of GFR [12] [13] [14] [15]. Thus the present study was undertaken to analyze the effects of serum $\mathrm{HbAlc}$, (which is a marker of glycemic status) estimated glomerular filtration rate (eGFR) (which is a marker of microvascular kidney disease secondary to various causes), carotid intima-media thickness (CIMT) in predicting CAD on coronary angiography (CAG).

\section{Methodology}

Ethics statement: A written informed consent was taken from the patients after explaining the nature of the study. The study was undertaken after the institutional ethics committee approval dated 1. 6. 2015 with IEC No.462 in $44^{\text {th }}$ IEC meeting held in SVIMS, Tirupati.

Study design: Prospective observational study.

Study period: July 2015-July 2016.

Study population: Study population was selected from the population of patients undergoing elective CAG in department of cardiology, Sri Venkateswara Institute of Medical sciences, Tirupati.

Inclusion criteria: Patients presenting with stable angina as well as acute coronary syndrome (ACS) [USA/NSTEMI/STEMI] and undergoing elective CAG were included in the study population.

Exclusion criteria: Patients with DM or HbAlc $>6.5 \%$, chronic kidney disease, post CABG/PCI, patients with congenital heart diseases and hemoglobinopathies have been excluded from the study.

Demographic and clinical data on age, gender, smoking habit, DM, and hypertension (HTN) was obtained at the time of admission. Serum HbAlc, Hemoglobin ( $\mathrm{Hb}$ ), Serum Creatinine (SCr) blood urea (Bur) were measured from 
the sample drawn at the time of admission. Serum HbA1c was measured by ion exchange chromatography method using BIO-RAD D-10 hemoglobin testing system.

Estimated glomerular filtration rate (eGFR) was measured by Modification of Diet in Renal Disease (MDRD) equation [16]:

$$
\operatorname{eGFR}\left(\mathrm{mL} / \mathrm{min} / 1.73 \mathrm{~m}^{2}\right)=186 \times \mathrm{sCr}^{-1.154} \times \operatorname{age}^{-0.203} \times 0.742(\text { if female })
$$

Carotid intima-media thickness (CIMT): Bilateral common carotid arteries of the subjects were scanned longitudinally with $\mathrm{L} 11-3 \mathrm{MHz}$ linear transducer attached to PHILIPS IE 33 machine. Images were obtained from the distal portion of the common carotid artery, $1-2 \mathrm{~cm}$ proximal to the carotid bulb. Only arterial wall intima-media thickness of the distal $1 \mathrm{~cm}$ portion of the common carotid artery, just before bifurcation, was measured at end-diastole. The mean of left and right common carotid arteries was used for analysis.

Coronary artery angiography (CAG): Coronary artery angiography was performed using standard Judkins technique through trans-femoral or trans-radial approach. According to the baseline diagnostic angiogram, each coronary lesion having a stenosis obstructing $\geq 50 \%$ of the diameter in vessels $\geq 1.5 \mathrm{~mm}$ was scored separately and these scores were added together to produce the overall SYNTAX score (SX score) which was calculated using the SX score algorithm available on the SYNTAX website. Angiographic analysis was carried out by interventional cardiologist who was blinded to the study protocol.

Statistical analysis: The continuous and categorical variables were presented as the mean \pm standard deviation (SD) and proportions respectively. Intergroup differences of continuous variables were analyzed by t-test. Spearman correlation and linear regression were used in the analysis of the data. Receiver operating characteristic (ROC) curve was constructed to calculate cutoff values, area under curve (AUC) sensitivity and specificity. All data was processed using the SPSS version 20 (IBM SPSS, IBM Inc. Armonk, USA) statistical software. A $p$-value $<0.05$ was considered to be significant.

\section{Results}

The study population consisted of 450 patients, out of which 79 (17.6\%) were female and $371(82.4 \%)$ were male. One third of the patients $(30.2 \%)$ had hypertension and half of them (50.4\%) were smokers. STEMI was seen in 176 patients (39\%). On coronary angiography 122 patients (27.1\%) had no obstructive coronary disease and $\mathrm{CAD}$ was identified in 328 patients $(72.9 \%)$. Percutaneous coronary intervention (PCI) was done in 258 patients $(57.6 \%)$ and coronary artery bypass grafting (CABG) was done in 50 patients (11.1\%) (Table 1).

Mean age of the study population was $52.8 \pm 10.9$ years, mean eGFR was 83.7 $\pm 25.1 \mathrm{ml} / \mathrm{min} / 1.73 \mathrm{~m}^{2}$, mean SX score was $9.2 \pm 9.1$ and mean HbA1c was $5.7 \%$ $\pm 0.6 \%$ (Table 1 ).

In the total study population of 450 subjects, 328 had CAD on coronary angiography, this group was labeled as CAD group and the subjects with no CAD on 
Table 1. Baseline data.

\begin{tabular}{|c|c|}
\hline Categorical variables & Frequency $n=450(\%)$ \\
\hline \multicolumn{2}{|l|}{ Gender } \\
\hline o Male & $371(82.4)$ \\
\hline Female & $79(17.6)$ \\
\hline \multicolumn{2}{|l|}{ CAD on angiography } \\
\hline 0 Present & $328(72.9)$ \\
\hline o Absent & $122(27.1)$ \\
\hline Hypertension & $136(30.2)$ \\
\hline Smoking & $228(50.4)$ \\
\hline STEMI & $176(39)$ \\
\hline \multicolumn{2}{|l|}{ Management } \\
\hline o $\mathrm{CABG}$ & $50(11.1)$ \\
\hline PTCA & $258(57.6)$ \\
\hline Medical management & $142(31.6)$ \\
\hline SYNTAX category & \\
\hline 0 & $122(27.1)$ \\
\hline$\leq 22$ & $280(62.2)$ \\
\hline $0>22$ & $48(10.6)$ \\
\hline Continuous variable & Mean \pm SD \\
\hline Age (years) & $52.8 \pm 10.9$ \\
\hline eGFR $\left(\mathrm{ml} / \mathrm{min} / 1.73 \mathrm{~m}^{2}\right)$ & $83.7 \pm 25.1$ \\
\hline $\mathrm{SCr}(\mathrm{mg} / \mathrm{dl})$ & $0.93 \pm 0.22$ \\
\hline BMI $\left(\mathrm{kg} / \mathrm{m}^{2}\right)$ & $23.2 \pm 3.6$ \\
\hline CIMT (mm) & $0.77 \pm 0.20$ \\
\hline $\mathrm{Hb}(\mathrm{gm} \%)$ & $12.7 \pm 1.9$ \\
\hline HbAlc (\%) & $5.7 \pm 0.6$ \\
\hline Platelet count (lakhs $\left./ \mathrm{cm}^{3}\right)$ & $2.6 \pm 0.7$ \\
\hline Bur (mg/dl) & $26.6 \pm 9.2$ \\
\hline $\mathrm{EF}(\%)$ & $51.2 \pm 9.9$ \\
\hline SX score & $9.2 \pm 9.1$ \\
\hline
\end{tabular}

Study population characteristics.

angiography were considered under Non-CAD group. There was a statistically significant difference in the means of CIMT $(0.80 \pm 0.22,0.69 \pm 0.13, p=0.005)$, HbAlc (5.7 $\pm 0.5,5.5 \pm 0.4, p=0.001), \mathrm{SCr}(0.96 \pm 0.20,0.86 \pm 0.20, p=0.001)$, eGFR $(80.8 \pm 22.9,91.3 \pm 28.9, p=0.001)$, and patients age (54.1 $\pm 10.6,49.2 \pm$ 10.7, $p=0.001$ ) among the CAD and Non-CAD groups (Table 2 and Figure 1).

On Spearman correlation analysis, significant positive correlation was observed between HbA1c $(r=0.242, p=0.001)$, CIMT $(r=0.231, p=0.001)$, SCr 

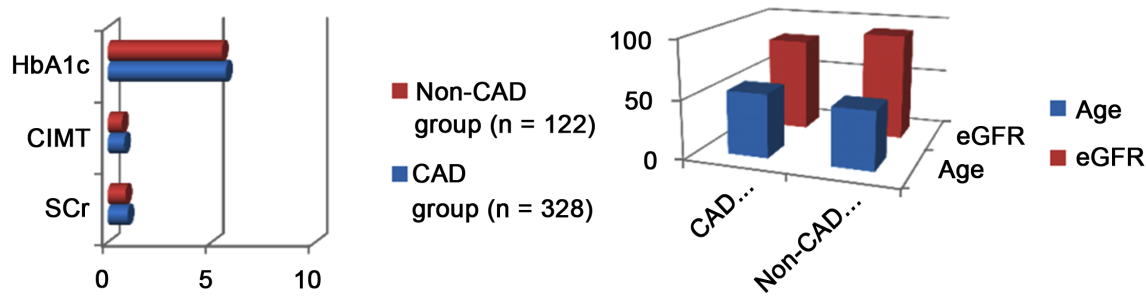

Figure 1. Distribution of variables among CAD and Non-CAD groups.

Table 2. Comparison of means among CAD and Non-CAD groups.

\begin{tabular}{cccc}
\hline Variable & $\begin{array}{c}\text { CAD group }(\mathbf{n}=\mathbf{3 2 8}) \\
(\text { Mean } \pm \text { SD) }\end{array}$ & $\begin{array}{c}\text { Non-CAD group }(\mathbf{n}=122) \\
(\text { Mean } \pm \text { SD) }\end{array}$ & $p$-value \\
\hline Age & $54.1 \pm 10.6$ & $49.2 \pm 10.7$ & 0.001 \\
eGFR & $80.8 \pm 22.9$ & $91.3 \pm 28.9$ & 0.001 \\
SCr & $0.96 \pm 0.20$ & $0.86 \pm 0.20$ & 0.002 \\
BMI & $23.1 \pm 3.6$ & $23.6 \pm 3.6$ & 0.212 \\
CIMT & $0.80 \pm 0.22$ & $0.69 \pm 0.13$ & 0.005 \\
HbAlc & $5.7 \pm 0.5$ & $5.5 \pm 0.4$ & 0.001 \\
Hb & $12.8 \pm 1.9$ & $12.5 \pm 2.0$ & 0.127 \\
Platelet count & $2.60 \pm 0.75$ & $2.60 \pm 0.74$ & 0.694 \\
\hline
\end{tabular}

$(r=0.202, p=0.001)$, patient's age $(\mathrm{r}=0.148, p=0.002)$ and CAD, whereas eGFR ( $\mathrm{r}=-0.148, p=0.002)$ was negatively correlated with CAD on angiography (Table 3). On Linear Regression analysis, CIMT, eGFR, HbAlc and patient's age were independently predicting CAD on angiography and these variables collectively predicted $36 \%$ of change in the SX score (Table 4 ).

Patient's age $>56$ years, $(\mathrm{AUC}=0.622)$, CIMT $>0.86 \mathrm{~mm}(\mathrm{AUC}=0.642)$, $\mathrm{HbAlc}>6,(\mathrm{AUC}=0.620), \mathrm{eGFR}<92 \mathrm{ml} / \mathrm{min} / 1.73 \mathrm{~m}^{2}$ (AUC=0.601) were the cutoff values obtained by ROC curve analysis for predicting CAD on coronary angiograph (Table 5 and Figure 2).

\section{Discussion}

In previous studies HbA1c levels, eGFR and CIMT have been individually correlated with $\mathrm{CAD}$ on angiography. In the present study we have analyzed the effect and strength of correlation of these variables with CAD.

$\mathrm{HbA1C}$ and CAD: The mean $\mathrm{HbAlc}$ in the CAD patients in the present study is $5.7 \%$, which is statistically different compared to patients with normal coronaries (5.5\%) (Table 2). Similar findings were reported by Iqra Mehraj et al. in their study on Kashmiri Indians [17]. A study by Selim Ayhan et al. [18] in Turkey population showed the optimal cut-off value of HbAlc to predict severe CAD was $6.5 \%$, with $74.4 \%$ sensitivity and $75.1 \%$ specificity on ROC curve analysis. A study by En-Zhi Jia et al. [19] in Chinese subjects showed that the optimal cutoff value of $\mathrm{HbAlc}$ for predicting $\mathrm{CAD}$ was $>5.1$ with sensitivity and specificities of $72 \%, 75 \%$ respectively. A similar study done on Indians by James 

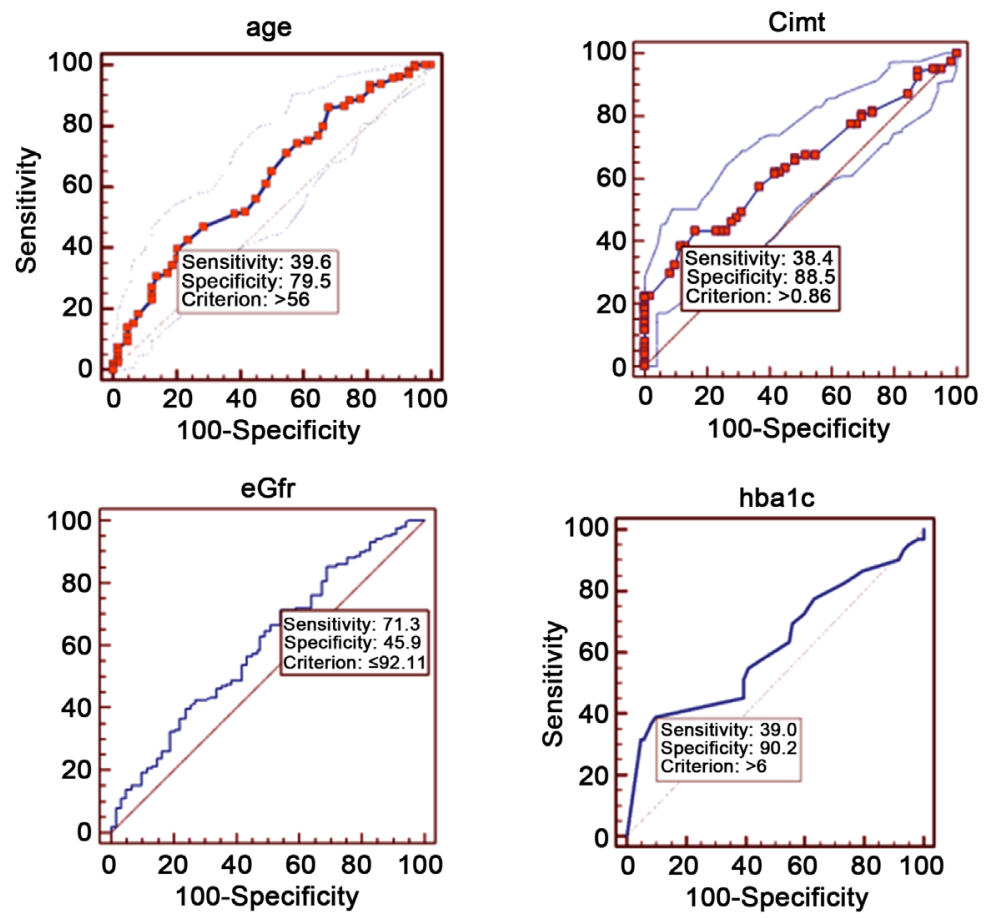

Figure 2. ROC curve analysis.

Table 3. Spearman correlations.

\begin{tabular}{ccc}
\hline Variable vs. SX score & R value & $p$-value \\
\hline Age & 0.148 & 0.002 \\
SCr & 0.202 & 0.001 \\
eGFR & -0.148 & 0.002 \\
BMI & -0.036 & 0.447 \\
CIMT & 0.231 & 0.001 \\
HbAlc & 0.242 & 0.001 \\
\hline
\end{tabular}

Table 4. Linear regression analysis.

\begin{tabular}{ccccc}
\hline Model & R & R square & Adjusted R square & Std error of estimate \\
\hline 1 & $0.275^{\mathrm{a}}$ & 0.076 & 0.074 & 0.685 \\
2 & $0.345^{\mathrm{b}}$ & 0.119 & 0.115 & 0.670 \\
3 & $0.368^{\mathrm{c}}$ & 0.135 & 0.130 & 0.664 \\
\hline
\end{tabular}

apredictors: (constant), CIMT; ${ }^{b}$ predictors: (constant),CIMT, eGFR; ' predictors: (constant), CIMT, eGFR, HbAlc; Dependant variable: SX score.

Table 5. ROC curve analysis.

\begin{tabular}{ccccc}
\hline Variable & Sensitivity & Specificity & Criteria & AUC \\
\hline Patients age & 39.6 & 79.5 & $>56$ years & 0.622 \\
CIMT & 38.4 & 88.5 & $>0.86 \mathrm{~mm}$ & 0.642 \\
eGFR & 71.3 & 45.9 & $<92.1 \mathrm{ml} / \mathrm{min} / \mathrm{m}^{2}$ & 0.601 \\
HbAlc & 39.0 & 90.2 & $>6$ & 0.620 \\
\hline
\end{tabular}


Dilley et al. [20] showed that HbA1c was significantly correlated with the prevalence of $\mathrm{CAD}$. In the same study, $\mathrm{HbA1c}$ value of $>5.6 \%$ predicted $\mathrm{CAD}$ with sensitivity and specificities of $56 \%, 67.6 \%$ respectively. Similarly in present study $\mathrm{HbAlc}$ is independently correlated with presence of CAD on angiography, the observed cutoff value of $\mathrm{HbA1c}$ on ROC curve analysis for predicting CAD is $6 \%$ with sensitivity $39 \%$ and specificity $90 \%$ (Table 5 and Figure 2).

CIMT and CAD: CIMT is a valid marker of early atherosclerosis and thus has the potential to detect CVD in its subclinical phase. Several studies have shown that CIMT is strongly associated with cardiovascular risk factors [21] [22] [23] [24]. It possibly reflects the cumulative deleterious effects of various cardiovascular risk factors over time. The Chennai Urban Population Study [21] reported mean IMT values in non-diabetic subjects as $0.74 \pm 0.14 \mathrm{~mm}$ which is in agreement with the mean CIMT value in the present study $(0.77 \pm 0.02)$. In the Atherosclerosis Risk in Communities (ARIC) study [24], carotid far-wall IMT was consistently greater in those with clinical cardiovascular disease than in disease-free controls. Visona and colleagues [25] showed that CIMT in CAD patients $(1.45 \pm 0.95)$ was significantly higher than in controls $(0.87 \pm 0.1 ; p<$ 0.005). Hansa et al. [26] reported association of CIMT with CAD and CV risk factors in the Indian population, CIMT measured on each side, was significantly higher in the coronary disease group compared to the controls. In this respect, the results of present study $(0.80 \pm 0.22,0.69 \pm 0.13, p<0.005)$ (Table 2$)$ are in agreement with previous studies showing a significant association between raised CIMT and the presence of CAD.

In a recent systematic review, most of the studies showed a graded positive relationship between CIMT and angiographically assessed coronary atherosclerosis with correlation coefficients in the order of 0.3 - 0.4 [27]. Similarly in present study there is a significant positive correlation observed between the CIMT and presence of CAD on angiography with a correlation coefficient $\mathrm{r}=$ $0.231(p<0.001)$ (Table 3$)$.

In Framingham study [28], cut-off value of mean IMT of $0.9 \mathrm{~mm}$ predicted the presence of CAD, this is in accordance with the present study, where CIMT value of $>0.86 \mathrm{~mm}$ is associated with CAD in present study population (Table $5)$.

eGFR and CAD: Renal dysfunction is an independent risk factor for the development of CAD as shown in various studies. In the ARIC study [24], the level of GFR acted as an independent risk factor for atherosclerotic cardiovascular disease. In a study by Rahman M et al. [12], a low eGFR independently predicted increased risk for CAD. In the present study eGFR value in CAD patients differed significantly from that of patients with normal coronaries on CAG (80.8 \pm $22.9,91.3 \pm 28.9, p<0.001$ ), CAD patients tend to have low eGFR (Table 2). In a study by Jos'e Pedro L et al. [29], a relatively weak but significant negative correlation was found between eGFR and CAD burden on angiography $(\mathrm{r}=-0.26, p$ $=0.006)$, this is in agreement with the observed negative correlation of eGFR with CAD in present study $(\mathrm{r}=-0.148, p<0.02)$ (Table 3$)$. 
Though the strength of correlation is small, the increase in the HbAlc, CIMT values and decrease in the glomerular filtration rate predicted CAD on angiography as explained by Spearman correlation analysis (Table 3). HbA1c, CIMT were shown to have relatively high specificity and eGFR had relatively high sensitivity in predicting CAD in present study (Table 5 and Figure 2).

\section{Conclusions}

- CIMT, HbAlc, eGFR and patient's age at the time of admission predict CAD in non-diabetic patients undergoing coronary angiography.

- Patients with age more than 56 years, CIMT more than $0.86 \mathrm{~mm}, \mathrm{HbAlc}$ more than $6 \%$, and eGFR less than $92 \mathrm{ml} / \mathrm{min} / \mathrm{m}^{2}$ are most likely to have obstructive CAD on CAG.

- CIMT has relatively high specificity for identifying CAD patients.

\section{References}

[1] Gupta, R., Joshi, P., Mohan, V., Reddy, K.S. and Yusuf, S. (2008) Epidemiology and Causation of Coronary Heart Disease and Stroke in India. Heart, 94, 16-26.

https://doi.org/10.1136/hrt.2007.132951

[2] Ajay, V.S. and Prabhakaran, D. (2010) Coronary Heart Disease in Indians: Implications of the INTERHEART Study. Indian Journal of Medical Research, 132, 561-566.

[3] Misra, A., Nigam, P., Hills, A.P., et al. (2012) Consensus Physical Activity Guidelines for Asian Indians. Diabetes Technology \& Therapeutics, 14, 83-98.

https://doi.org/10.1089/dia.2011.0111

[4] Deepa, R., Arvind, K. and Mohan, V. (2002) Diabetes and Risk Factors for Coronary Artery Disease. Current Science, 83, 1497-505.

[5] Castelli, W.P. (1988) Cardiovascular Disease in Women. American Journal of Obstetrics \& Gynecology, 158, 1553-1560.

https://doi.org/10.1016/0002-9378(88)90189-5

[6] Cho, E., Rimm, E.B., Stampfer, M.J., Willett, W.C. and Hu, F.B. (2002) The Impact of Diabetes Mellitus and Prior Myocardial Infarction on Mortality from All Causes and from Coronary Heart Disease in Men. Journal of the American College of Cardiology, 40, 954-960. https://doi.org/10.1016/S0735-1097(02)02044-2

[7] Rossing, P., Hougaard, P., Borch-Johnsen, K. and Parving, H.H. (1996) Predictors of Mortality in Insulin Dependent Diabetes: 10 Year Observational Follow Up Study. BMJ, 313, 779-784. https://doi.org/10.1136/bmj.313.7060.779

[8] Gall, M.A., Borch-Johnsen, K., Hougaard, P., Nielsen, F.S., Parving, H.H. (1995) Albuminuria and Poor Glycemic Control Predict Mortality in NIDDM. Diabetes, 44, 1303-1309. https://doi.org/10.2337/diab.44.11.1303

[9] Sarnak, M.J., Levey, A.S., Schoolwerth, A.C., et al. (2003) Kidney Disease as a Risk Factor for Development of Cardiovascular Disease: A Statement from the American Heart Association Councils on Kidney in Cardiovascular Disease, High Blood Pressure Research, Clinical Cardiology, and Epidemiology and Prevention. Circulation, 108, 2154-2169. https://doi.org/10.1161/01.CIR.0000095676.90936.80

[10] Muntner, P., He, J., Hamm, L., Loria, C. and Whelton, P.K. (2002) Renal Insufficiency and Subsequent Death Resulting from Cardiovascular Disease in the United 
States. Journal of the American Society of Nephrology, 13, 745-753.

[11] Foley, R.N., Murray, A.M., Li, S., Herzog, C.A., McBean, A.M. and Eggers, P.W. (2005) Chronic Kidney Disease and the Risk for Cardiovascular Disease, Renal Replacement, and Death in the United States Medicare Population, 1998 to 1999. Journal of the American Society of Nephrology, 16, 489-495. https://doi.org/10.1681/ASN.2004030203

[12] Rahman, M., Pressel, S., Davis, B.R., et al. (2006) Cardiovascular Outcomes in High-Risk Hypertensive Patients Stratified by Baseline Glomerular Filtration Rate. Annals of Internal Medicine, 144, 172-180. https://doi.org/10.7326/0003-4819-144-3-200602070-00005

[13] van der Velde, M., Matsushita, K., Coresh, J., et al. (2011) Lower Estimated Glomerular Filtration Rate and Higher Albuminuria Are Associated with All-Cause and Cardiovascular Mortality. A Collaborative Meta-Analysis of High-Risk Population Cohorts. Kidney International, 79, 1341-1352. https://doi.org/10.1038/ki.2010.536

[14] Segura, J., Campo, C., Gil, P., et al. (2004) Development of Chronic Kidney Disease and Cardiovascular Prognosis in Essential Hypertensive Patients. Journal of the American Society of Nephrology, 15, 1616-1622. https://doi.org/10.1097/01.ASN.0000127045.14709.75

[15] Knobler, H., Zornitzki, T., Vered, S., et al. (2004) Reduced Glomerular Filtration Rate in Asymptomatic Diabetic Patients: Predictor of Increased Risk for Cardiac Events Independent of Albuminuria. Journal of the American College of Cardiology, 44, 2142-2148. https://doi.org/10.1016/j.jacc.2004.09.006

[16] Levey, A.S., Bosch, J.P., Lewis, J.B., Greene, T., Rogers, N. and Roth, D. (1999) A More Accurate Method to Estimate Glomerular Filtration Rate from Serum Creatinine: A New Prediction Equation. Modification of Diet in Renal Disease Study Group. Annals of Internal Medicine, 130, 461-470. https://doi.org/10.7326/0003-4819-130-6-199903160-00002

[17] Mehraj, I., et al. (2014) Association of HbAlc with Prevalence and Severity of Coronary Artery Disease in Diabetic and Non-Diabetic Patients in Kashmir. Asian Journal of Science and Technology, 5, 230-232.

[18] Ayhan, S.S., et al. (2012) Glycated Haemoglobin Is Correlated with the Severity of Coronary Artery Disease Independently of Traditional Risk Factors in Young Patients. Polish Journal of Endocrinology, 63, 367-371.

[19] Jia, E.-Z., et al. (2014) Hemoglobin A1c Risk Score for the Prediction of Coronary Artery Disease in Subjects with Angiographically Diagnosed Coronary Atherosclerosis. Cellular Physiology and Biochemistry, 34, 672-680. https://doi.org/10.1159/000363032

[20] Dilley, J., et al. (2007) Association of A1C with Cardiovascular Disease and Metabolic Syndrome in Asian Indians with Normal Glucose Tolerance. Diabetes Care, 30, 1527-1532. https://doi.org/10.2337/dc06-2414

[21] Mohan, V., Ravikumar, R., Shanthi Rani, S. and Deepa, R. (2000) Intima-Media Thickness of the Carotid Artery in South Indian Diabetic \& Non-Diabetic Subjects: The Chennai Urban Population Study (CUPS). Diabetologia, 43, 494-499. https://doi.org/10.1007/s001250051334

[22] Heiss, G., Sharrett, A.R., Barnes, R., Chambless, L.E., Szklo, M. and Alzola, C. (1991) Carotid Atherosclerosis Measured by B-Mode Ultrasound in Populations: Associations with Cardiovascular Risk Factors in the ARIC Study. American Journal of Epidemiology, 134, 250-256.

https://doi.org/10.1093/oxfordjournals.aje.a116078 
[23] Kuller, L., Borhani, N., Furberg, C., Gardin, J., Manolio, T., O’Leary, D., et al. (1994) Prevalence of Subclinical Atherosclerosis and Cardiovascular Disease and Association with Risk Factors in the Cardiovascular Health Study. American Journal of Epidemiology, 139, 1164-1179. https://doi.org/10.1093/oxfordjournals.aje.a116963

[24] Burke, G.L., Evans, G.W., Riley, W.A., Sharrett, A.R., Howard, G., Barnes, R.W., et al. (1995) Arterial Wall Thickness Is Associated with Prevalent Cardiovascular Disease in Middle-Aged Adults. The Atherosclerosis Risk in Communities (ARIC) Study. Stroke, 26, 386-391. https://doi.org/10.1161/01.STR.26.3.386

[25] Visona, A., Pesavento, R., Lusiani, L., Bonanome, A., Cernetti, C., Rossi, M., et al. (1996) Intimal Medial Thickening of Common Carotid Artery as Indicator of Coronary Artery Disease. Angiology, 47, 61-66. https://doi.org/10.1177/000331979604700109

[26] Hansa, G., Bhargava, K., Bansal, M., Tandon, S. and Kasliwal, R.R. (2003) Carotid Intima-Media Thickness and Coronary Artery Disease: An Indian Perspective. Asian Cardiovascular and Thoracic Annals, 11, 217-221. https://doi.org/10.1177/021849230301100308

[27] Bots, M.L., Baldassarre, D., Simon, A., de Groot, E., O’Leary, D.H., Riley, W., et al. (2007) Carotid Intima-Media Thickness and Coronary Atherosclerosis: Weak or Strong Relations? European Heart Journal, 28, 398-406.

https://doi.org/10.1093/eurheartj/ehl482

[28] Budoff, M. (2011) Atherosclerosis: Should We Use CIMT Testing? New Insights from Framingham. Nature Reviews Cardiology, 8, 615-616. https://doi.org/10.1038/nrcardio.2011.144

[29] Jos'e Pedro, L., et al. (2007) Glomerular Filtration Rate and Coronary Artery Disease Burden in Patients with Acute Coronary Syndrome. Clinical Cardiology, 30, 464-468. https://doi.org/10.1002/clc.20145 